\title{
Loss minimization DTC electric motor drive system based on adaptive ANN strategy
}

\author{
Sim Sy Yi ${ }^{1}$, Wahyu Mulyo Utomo ${ }^{2}$, Goh Hui Hwang ${ }^{3}$, Chien Siong Kai ${ }^{4}$, Alvin John Lim Meng Siang ${ }^{5}$, \\ Nor Aira Zambri', Yonis M. Y. Buswig ${ }^{7}$, Kah Haw Law ${ }^{8}$, Sim Gia Yi ${ }^{9}$ \\ ${ }^{1,4,6}$ Faculty of Engineering Technology, Universiti Tun Hussein Onn Malaysia, Malaysia \\ ${ }^{2,9}$ Faculty of Electrical and Electronic Engineering, Universiti Tun Hussein Onn Malaysia, Malaysia \\ ${ }^{3}$ School of Electrical Engineering, Guangxi University, Malaysia \\ ${ }^{5}$ Faculty of Civil and Environmental Engineering, Universiti Tun Hussein Onn Malaysia, Malaysia \\ ${ }^{7}$ Faculty of Engineering, Universiti Malaysia Sarawak, Malaysia \\ ${ }^{8}$ Department of Electrical and computer Engineering, Curtin University Malaysia, Malaysia
}

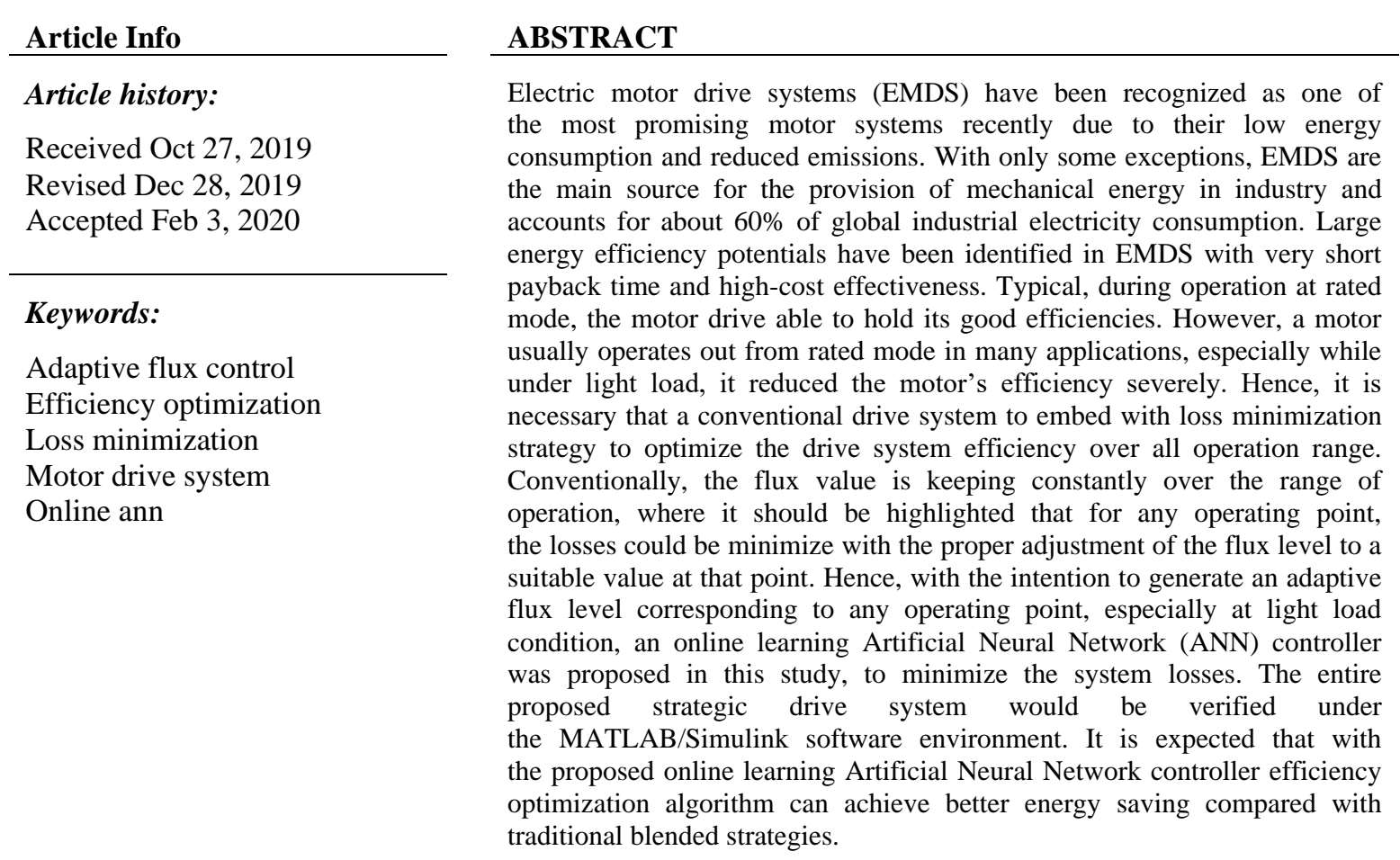

This is an open access article under the CC BY-SA license.

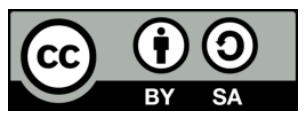

\section{Corresponding Author:}

Sim Sy Yi,

Department of Electrical Engineering Technology,

Faculty of Engineering Technology,

Universiti Tun Hussein Onn Malaysia, 86400 Parit Raja, Johor, Malaysia.

Email: sysim@uthm.edu.my

\section{INTRODUCTION}

In an effort moving towards new era of mechanization, realization of more precision and accuracy work can be attain by replaced the human with machines [1]. Electric drives have been getting popular and 
deployed in various of application which involved motion. In drive systems, a prime mover are necessary in order to generate energy that is used to create motion. This highlights in an enormous energy saving potential by energy-efficient electrical drive solutions [2]. This energy gain from different sources such as diesel and petrol engines, hydraulic motors and electric motors etc. Drives in which electric motors are the prime movers are known as electrical drives [1]. Plenty of advantages are reported by implement electric drives, such as nimble control, less maintainance, high efficiency, extensive limits of power, speed and torque, low noise, and neat operation.

A total of $65-70 \%$ total electricity supply to industry is consumed by the electric motor globally. It is expected to have a considerable amount of saving in energy price and reduction in coal consumption and greenhouse emission by having only $1 \%$ achievement in increasing electric motor efficiency. With the completeness implementation of the proper efficiency optimization technique, it is expected to have $7 \%$ lower electricity deman in globe, reported by various international agencies of developing countries [3, 4]. Operating of motor in unrated condition, especially partial loading for an extended time is the main reasons resulting in low energy efficiency in electric drive system, as compared to others factors. As make know in electric power research institute (EPRI), most of the period of time, 60- 65\% of electric motor operates in industry are $60 \%$ below the rated load. That is, under rated condition, $35-40 \%$ of the motors is endlessly wasting the electricity due to the poor efficiency [5, 6], and seems to be focused as wide area for energysaving and energy-efficient concept [7]. As per report in a Malaysia commercial building, it is close to 50\% of electricity consumed in HVAC application, the induction motors are normally operated in unrated condition for a prolonged time [1]. Hence, an energy efficient control strategy are needed to ensure the maximum generated energy can be consumed[8-10].In order to fulfil the efficiency enhancement, some studies proposed high-quality materials, design and construction techniques [10]. Nevertheless, there is other valued solution, namely expert control algorithm which able to apply directly to a drive system [11].

In most cases, the electric motor are design and develop to run at 50-100\% of rated load [5], which in turn hold a maximum efficiency when operating near to rated condition [12]. However, one efficiency is badly reduced [13,14] due to over-excitation [8] while at partial load, which results in excessive in iron losses. Therefore, an energy efficient optimal control, a strategy that work for adjusting the flux level according to load changes to achieve maximum efficiency is required [5].which is also refer as efficiency optimization control.

Numerous of strategis has been reported to optimize efficiency for EMDS particularly at light load. Generally, the real-time optimization control technique of EMDS efficiency cab be assort as (1) Search Control (SC), and (2) Loss-Model-Based Control (LMC). The principal ideology for these methods is to alternate the amplitude of the flux with varies of motor operating condition although these two controls have different execution [15-17]. In SC, IM's power input or DC link power will be used in the optimization process. It manipulates the control input irrespective of motor parameter to minimize the input power from the measured current and voltage. This method worked on the basic to alternate the flux level in the drive system until the minimum power input is achieved for one point of operation [18-19]. The malpractice of this approach is that it denote a rather long response time and a slow convergence to the optimal value. In addition, the capability of SC is muchly depends on the input power quality. On the other hand, Loss model controller, LMC works depend on the motor parameter. It used the IM drive losses model to determine the optimum flux level which minimize the losses of the drive system for a given load and speed. This methods is free from power measurements but it utilize feedback [16, 20-21], yet, the LMC performance is greatly depends on motor drive modelling and it's losses. Development of LMC exist a trade-off between system complexity and accuracy $[15,22-24]$.

Therefore, the aim for this study is to designing a robust efficiency optimization control to predict the minimum flux value, at any operating point over the entire selected drive system speed range that able to maximize the drive's efficiency and maintain the system performance at the same time.

\section{CHARACTERIZATION OF MAXIMUM ENERGY EFFICIENCY ACHIEVEMENT}

Virtually, EM shows best transient response and impose high efficiency when operate at its rated torque and speed. However, EM works far from its rated condition in most of the application, especially at minimum load levels, which the initial value of the reference flux is kept, where it give rise to some problems in the drive systems. Owing to the imbalance between copper and iron losses at light loads, rated flux operation causes large core lose, thus reducing the efficiency of the drive $[25,26]$. At a certain operating point, the efficiency of the EM can be improved by reducing to a minimum loss and decreasing the level of the magnetic flux appropriately or by balancing the copper and iron losses through programming the flux. As it is known, the losses of an electromagnetic in a machine are a direct function of the magnetic flux, 
therefrom, with an appropriate flux level calibration, the proportionate balance of losses between the copper and iron could be obtained. Hence, the air gap flux must be minimize to enhance the motor efficiency.

From the basic of the motor's torque is formed by the torque producing rotor current and magnetizing current, it is workable with different combination of current and flux value to gain the same torque value. Ordinarily, the EM is designed to operate close to the rated load, however, there is an optimum flux value where the drive's maximum efficiency can be achieved for any operating speed and load condition. In a simple way, less efficient occurrences at low load conditions happens because of the unsuitability of the flux level selection and it could be improved in a way of calibrating based on the ANN based efficienc optimization control strategy

\section{DEVELOPMENT OF PROPOSED ANN BASED EFFICIENCY OPTIMIZATION CONTROL STRATEGY}

On the basic of the flux reduction, at a certain load, full efficiency can be obtained with the correct flux level adjustment to get an optimum flux value. Therefore, the first step for this study is to characterise the efficiency behaviour pattern for any possible operating mode in EMDS to obtain its respective optimum flux values that enable the maximum efficiency in the drive system. In this study, the energy efficiency optimization controller is proposed and designed based on the flux reduction concept by the implementation of Artificial Neural Network (ANN) [22-23]. The maximum efficiency of EMDS can be achieved when the minimum input power is obtained with the constant output power required by the load. This proposed approach is based on varying the flux up to the point where the measuring input power is a minimum of one point of operation. The adaptive optimum flux value is predicted by the proposed efficiency optimization ANN based efficiency optimization controller algorithm for any different operation mode, ie, various speed and various load to obtain its optimum flux value corresponding to different cases as shown in Figure 1. The prediction of the flux value can be achieved due to the possession of the online learning ability in the proposed algorithm. The difference between the calculated input and the real input power is fed as input for the neural. [26-28]

The proposed ANN based energy efficiency optimization of DTC EMDS, as shown in Figure 1, where it is targeted to maintain the fast dynamic characteristics and better response, and also aimed in getting minimum losses especially for the light load and light speed drive's operation.

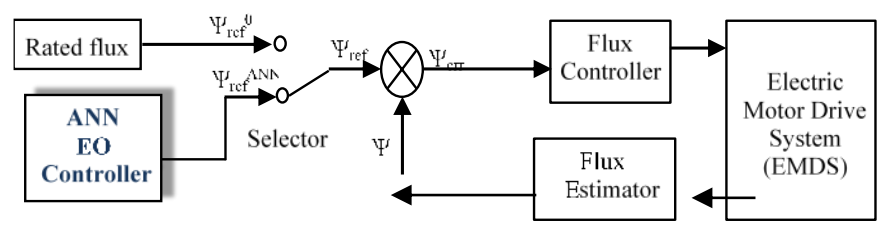

Figure 1. Block Diagram of the proposed ANN based energy efficiency optimization control EMDS.

\section{RESULTS AND ANALYSIS}

The proposed ANN efficiency optimization controller is shown in Figure 2. The error of input power is used as input for the proposed controller while the output of it implemented as the optimum flux reference.

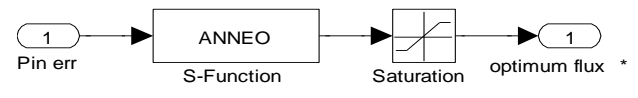

Proposed ANNEO Controller

Figure 2. Simulink circuit for the proposed ANN efficiency optimization controller.

In order to verify the effectiveness of the proposed ANN efficiency optimization controller for the DTC electric drive system, the investigations of the drive system have been carried out for different values of speed and torque. The effects of speed and torque variation on the system's efficiency as well as 
the capability of the drive system to maintain the good speed response achievement for variety speed and torque are tested.

The selection time is set at time $=0.5 \mathrm{~s}$ to activate the proposed ANN efficiency optimization controller to compare the efficiency performance before and after the proposed controller is injected into the system. The simulation results of motor speed of 1100 and 800 rpm tested with maximum and minimum torques applied, which are 0.2 and $0.8 \mathrm{Nm}$ respectively are given in Figure 3- 6 . The system response shown in Figure $3-6$, from top to bottom, represent the motor speed (rpm), the d-q axis voltage (V), the d-q axis current (A), optimal flux (Wb), and lastly the drive input power (W).

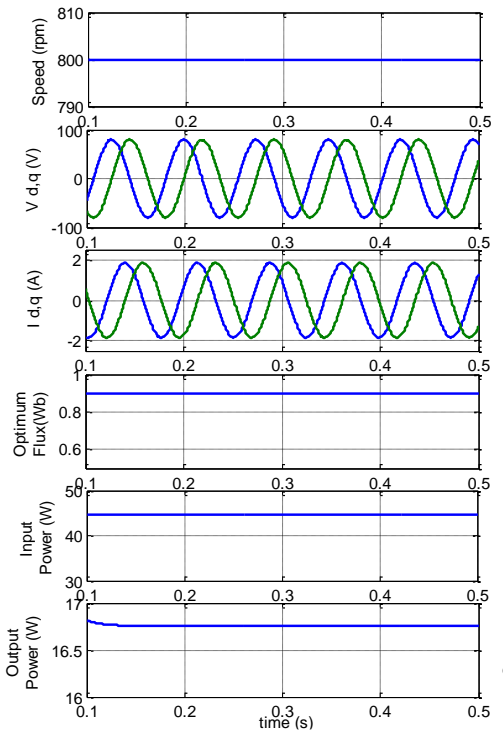

(a)

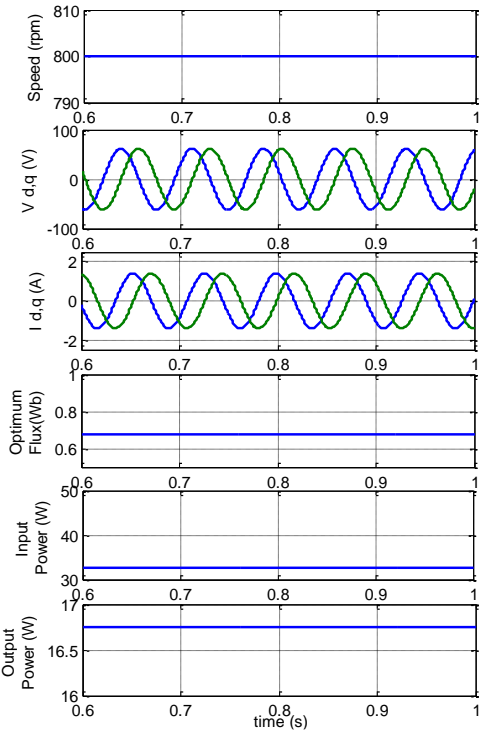

(b)

Figure 3. Drive system performance where the proposed ANN efficiency optimization controller is initiated at the time $=0.5 \mathrm{~s}$ at the motor speed of $800 \mathrm{rpm}$ with an applied $0.2 \mathrm{Nm}$ load torque (a) before the ANN efficiency optimization controller is initiated; (b)after the ANN efficiency optimization controller is initiated.

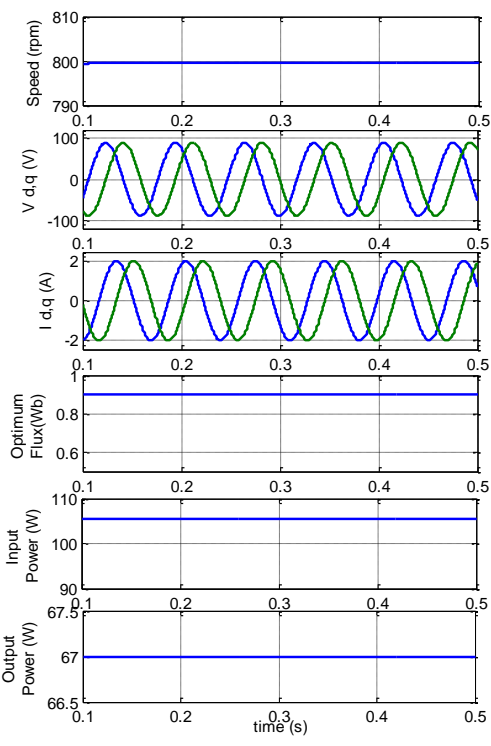

(a)

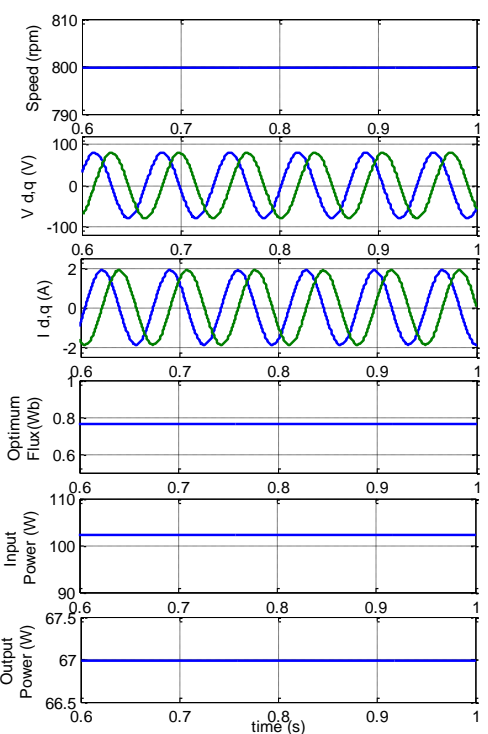

(b)

Figure 4. Drive system performance where the proposed ANN efficiency optimization controller is initiated at the time $=0.5 \mathrm{~s}$ at the motor speed of $800 \mathrm{rpm}$ with an applied $0.8 \mathrm{Nm}$ load torque (a) before the ANN efficiency optimization controller is initiated; (b)after the ANN efficiency optimization controller is initiated. 


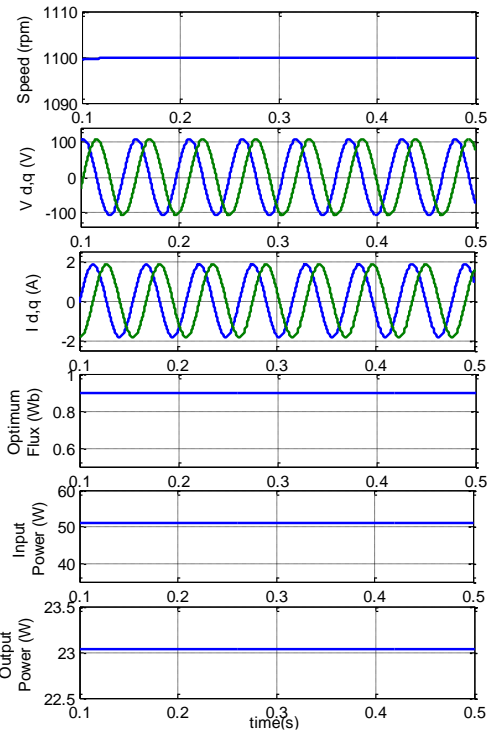

(a)

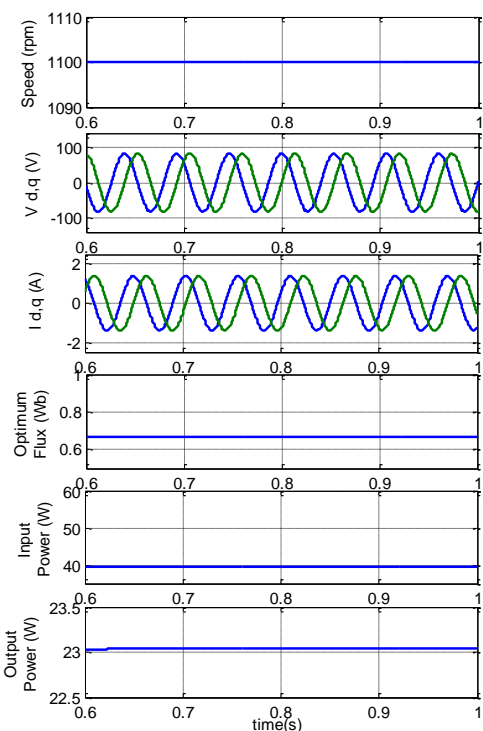

(b)

Figure 5. Drive system performance where the proposed ANN efficiency optimization controller is initiated at the time $=0.5 \mathrm{~s}$ at the motor speed of $1100 \mathrm{rpm}$ with an applied $0.2 \mathrm{Nm}$ load torque (a) before the ANN efficiency optimization controller is initiated; (b)after the ANN efficiency optimization controller is initiated.

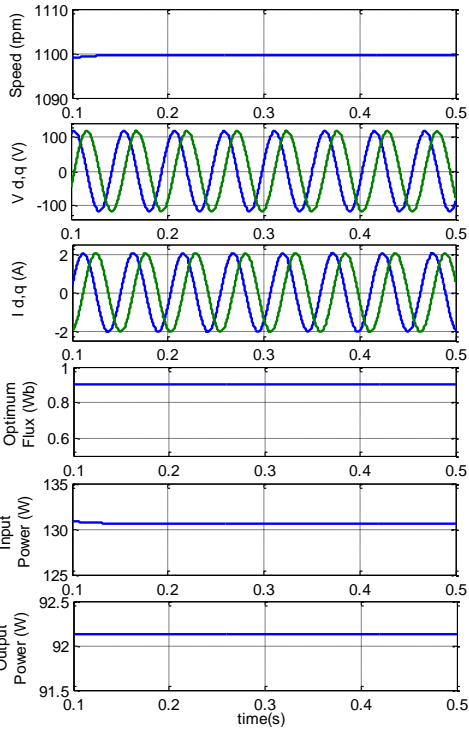

(a)


(b)

Figure 6. Drive system performance where the proposed ANN efficiency optimization controller is initiated at the time $=0.5 \mathrm{~s}$ at the motor speed of $1100 \mathrm{rpm}$ with an applied $0.8 \mathrm{Nm}$ load torque (a) before the ANN efficiency optimization controller is initiated; (b)after the ANN efficiency optimization controller is initiated.

The ANN efficiency optimization controller is aimed to produce an adaptive optimum flux value with respect to different speed under various torque level to gain the maximum drive efficiency, especially at light speed and light load operations. The resulting adaptive flux level generated from the ANN efficiency optimization for each tested operating condition is shown in Table 1, instead of a $0.9 \mathrm{Nm}$ constant reference flux. 
Table 1. Resulting flux level obtained by the proposed adaptive ANNEO for various operating condition.

\begin{tabular}{ccc}
\hline $\begin{array}{c}\text { Torque }(\mathrm{Nm}) \\
\text { Speed }(\mathrm{rpm})\end{array}$ & 0.2 & 0.8 \\
\hline 1100 & 0.6697 & Optimum Flux Level \\
800 & 0.6753 & 0.7468 \\
& & 0.7636 \\
\hline
\end{tabular}

\section{CONCLUSION}

This paper presents a strategy to optimise the efficiency for DTC Electric Motor Drive System. An ANN based energy efficiency optimization controller with the objective of generating an adaptive flux level to optimize the efficiency of different operating points has been proposed in this study. The proposed optimum flux controller is able to decrease stator flux rapidly from rated value of $0.9 \mathrm{~Wb}$ to its corresponding optimal value. Therefore, current and voltage will be reduced and thus minimizes the input power to achieve maximum efficiency of the drive system. At the same time, it is able to preserve good dynamic response of the drive system by maintaining the speed in constant according to speed reference command for different operating conditions of speed and torque. As a result, a significant efficiency improvement has been achieved by the optimal flux level determined by the proposed ANN based energy efficiency optimization compared with the constantly rated flux value, the objective of the study has been achieved.

\section{ACKNOWLEDGEMENTS}

The authors would like to thank the Ministry of Education, Ma-laysia (MOE) and the Research Management Centre (RMC), Uni-versiti Tun Hussein Onn Malaysia (UTHM) for financially sup-porting this research under the Fundamental Research Grant Scheme (FRGS) Vot.No. FRGS/1/2018/TK10/UTHM/03/8 and partially sponsored by Universiti Tun Hussein Onn Malaysia.

\section{REFERENCES}

[1] Woosuk Sung, Jincheol Shin, Yu-seok Jeong, "Energy-Efficient and Robust Control for High-Performance Induction Motor Drive With an Application in Electric Vehicles," IEEE transactions on vehicular technology, vol. 61, no. 8, Oct 2012.

[2] J. Austermann, H. Borcherding, H. Stichweh, V. Grabs, "High efficient modular drive system - An ideal approach for green intralogistics applications," 2016 18th European Conference on Power Electronics and Applications (EPE'16 ECCE Europe), Karlsruhe, pp. 1-10, 2016.

[3] T. Fletier, W. Eichhammer and J. Schleich, "Energy efficiency in electric motor systems: Technical potentials and policy approaches for developing countries," United Nations Industrial Development, Vienna, 2011.

[4] P. K. Choudhary and S. P. Dubey, "Efficiency optimization of induction motor drive in steady-state using Artificial Neural Network," 2016 International Conference on Computation of Power, Energy Information and Commuincation (ICCPEIC), Chennai, pp. 295-302, 2016.

[5] R. Razali, A. A. Abdalla, R. Ghoni and C. Venkataseshaiah, "Improving squirrel cage induction motor efficiency: technical review," International journal of physical sciences, vol. 7, no. 8, pp. 1129-1140, 16 Feb 2012.

[6] J. Malinowski, W. Hoyt, P. Zwanziger and B. Finley, "Review of upcoming motor and drive systems efficiency regulations in U.S. and Europe," IEEE Petroleum and Chemical Industry Committee Conference (PCIC), Houston, TX, 2015, pp. 1-8, 2015.

[7] A. M. Bazzi and P. T. Krein, "Review of methods for real-time loss minimization in induction machines," IEEE transactions on Industry application, vol. 46, no. 6, pp. 2319-2328, Nov/Dec 2010.

[8] B. Blanusa, "New trends in efficiency optimization of induction motor drives," university of Banja Luka, Bosnia and Herzegovina, 2010.

[9] J. F. Stumper, A. Dotlinger and R. Kennel, "Loss minimization of induction machines in dynamic operation," IEEE transactions on energy conversion, vol. 28, no. 3, pp. 726-735, Sept 2013.

[10] G. Cui, L. Liu, S. Li, P. Yang, F. Yang, L. Chen, and J. Dong, "Optimization Design of High Efficiency Variable Frequency Induction Motor Based on Finite Element Analysis," in International Conference on Electrical Machines and Systems, pp. 701-705, 2014.

[11] K. T. Chau, "Electric Vehicle Machines and Drives: Design, Analysis and Application," Wiley-IEEE Press, pp. 375, 2015.

[12] M. Gaiceanu, E. Rosu, R. Paduraru and T. Munteanu, "Vector-controlled optimal drive system for the induction motor," 4th International Symposium on Electrical and Electronics Engineering (ISEEE), Galati, 2013, pp. 1-6, 2013.

[13] Y. L. Karnavas, C. K. Vacharides and A. D. Karlis, "On the development of an on-site induction motor efficiency estimator framework," MedPower 2014, Athens, pp. 1-6, 2014.

[14] N. Kumar, T. R. Chelliah and S. P. Srivastava, "Adaptive control schemes for improving dynamic performance of efficiency-optimized induction motor drives," ISA Transactions, vol. 57, pp. 301-310, 2014. 
[15] M. Farasat and E. Karaman, "Efficiency-Optimized Hybrid Field Oriented and Direct Torque Control of Induction Motor Drive," in International Conference on Electrical Machines and Systems, no. 5, pp. 20-23, 2011.

[16] A. M. Bazzi, S. Member, and P. T. Krein, "Review of Methods for Real-Time Loss Minimization in Induction Machines," IEEE Transactions on Industry Applications, vol. 46, no. 6, pp. 2319-2328, 2010.

[17] S. T. Varghese and K. R. Rajagopal, "Economic and efficient induction motor controller for electric vehicle using improved scalar algorithm," 2016 IEEE 1st International Conference on Power Electronics, Intelligent Control and Energy Systems (ICPEICES), Delhi, India, pp. 1-7, 2016.

[18] A. Taheri, A. Rahmati, and S. Kaboli, "Efficiency Improvement in DTC of Six-Phase Induction Machine by Adaptive Gradient Descent of Flux," IEEE Transactions on Power Electronics, vol. 27, no. 3, pp. 1552-1562, 2012.

[19] Z. Qu, M. Ranta, M. Hinkkanen, and J. Luomi, "Loss-Minimizing Flux Level Control of Induction Motor Drives," IEEE Transactions on Industry Applications, vol. 48, no. 3, pp. 952-961, May 2012.

[20] F. Tazerart, N. Taïb, T. Rekioua, and D. Rekioua, "Direct Torque Control Optimization with Loss Minimization of Induction Motor," in International Conference on Electrical Sciences and Technologies in Maghreb, pp. 1-8, 2014.

[21] Islam, M.R., Sadhu, P.K., Islam, M.M. and Hossain, M.K., "Performance Analysis of a DTC and SVM Based Field-Orientation Control Induction Motor Drive," International Journal of Power Electronics and Drive Systems, vol. 5, no. 3, pp. 336, 2015.

[22] S. Y. Sim, W. M. Utomo, Z. A. Haron, A. A. Bohari, N. M. Zin, and R. M. Ariff, "Neural Network SVPWM-DTC of Induction Motor for EV Load Model," in Electrical Power, Electronics, Communications, Controls, and Informatics Seminar, vol. 00, no. c, pp. 23-28, 2014.

[23] S. Y. Sim, W. M. Utomo, Z. A. Haron, A. A. Bohari, and N. M. Zin, "Modeling of an Online ANN based DTC Speed Controller towards the Effect of Parameter Sensitivities," in The Third International Conference on Computer Engineering and Mathematical Sciences, no. Iccems, pp. 225-232, 2014.

[24] Krim, S., Gdaim, S., Mtibaa, A. and Mimouni, M. F., "FPGA-based implementation direct torque control of induction motor," International Journal of Power Electronics and Drive Systems, vol. 5, no. 3, pp. 293, 2015.

[25] Sim, S. Y., Utomo, W. M., Haron, Z. A., Bohari, A. A., Zin, N. M. and Ariff, R. M., "Induction motor drive based neural network direct torque control," In Information Technology Convergence Springer, Dordrecht, pp. 255-262, 2013.

[26] Utomo, W.M., Sim, S.Y., Haron, Z.A. and Zin, N.M., "Online adaptive flux control for space vector PWM-DTC IM drives towards optimum efficiency design," ARPN Journal of Engineering and Applied Sciences, 2015.

[27] Utomo, W.M., Zin, N.M., Haron, Z.A., Sim, S.Y., Bohari, A.A., Ariff, R.M. and Hanafi, D.. "Speed Tracking of Field Oriented Control Permanent Magnet Synchronous Motor Using Neural Network," International Journal of Power Electronics and Drive Systems, vol. 4, no. 3, pp. 290, 2014.

[28] Utomo, W.M., Sim, S.Y., Haron, Z.A., Boharia, A.A., Muhammad Zin, N., Mat Ariff, R. and Siswanto, W.A., AN "Improved DTC of an induction motor drive with neural network controller," International Journal of Mechanical \& Mechatronics Engineering, vol. 14, no. 2, pp. 54-59, 2014. 